\title{
Raising awareness about protection and control of nuclear materials held by "small-scale holders"
}

\author{
D. LADSOUS, E. COULIÉ, M. GIORGIO
}

(Manuscript received 12 July 2012, accepted 13 July 2012)

ABSTRACT In France, the activities carried out by the "small-scale holders" of nuclear materials are organized by a specific regulatory system which defines in a detailed way their obligations and the means of control of the government. The first part of the article presents the legal framework relating to the use of nuclear materials by small-scale holders in civilian fields. The importance of the declaration of the nuclear material inventory is clearly emphasized and must be prepared and transmitted to the Institute for Radiological Protection and Nuclear Safety (IRSN) every year. The second part describes how this declaration is used to provide basic information for the competent Ministry and the inspectors to check the correct application of the regulatory requirements relating to physical protection and to the control of nuclear materials. Finally, the last part presents the on-site inspections carried out by sworn and accredited inspectors under the authority of the competent Authority, which provide an overall picture and allow an evaluation of the risks of theft, loss or diversion of these materials.

Keywords: regulation / plutonium / uranium / thorium / tritium

\section{Overview of the French regulations}

France has developed a complete nuclear fuel cycle from mine to reprocessing plants. Along with nuclear activities, small quantities of nuclear materials are also used, outside the nuclear fuel cycle, in particular in industrial, medical and research sectors.

Considering its nuclear situation and conscious of its national and international commitments in terms of national public security and nuclear non-proliferation, the French government set up a national safeguard system under the competent Authority (Ministry of Ecology, Sustainable Development and Energy) which ensures protection and control of nuclear materials.

This system is based on specific regulation covering the entire civil nuclear field as well as the industrial, medical, research and education sectors. The main

IRSN, Direction de l'Expertise Nucléaire de Défense, 31 avenue de la Division Leclerc, 92260 Fontenay-aux-Roses, France. 
TABLE I

Mass thresholds of nuclear materials according to the decree of September 17, 2009.

exemption

déclaration

autorization

Plutonium
Uranium 233
Uranium $\geq 20 \%$
Uranium $<20 \%$
Natural U
Depleted U
Thorium *
Deuterium ** $^{*}$
Tritium
Lithium ( $\left.{ }^{6} \mathrm{Li}\right)$

$1 \mathrm{~g}$

$1 \mathrm{~g}$

$1 \mathrm{~g}$

$1 \mathrm{~g}$

$1 \mathrm{~kg}$

$1 \mathrm{~kg}$

$1 \mathrm{~kg}$

$1 \mathrm{~kg}$

$0,01 \mathrm{~g}$

$1 \mathrm{~g}$
$3 \mathrm{~g}$

$3 \mathrm{~g}$

$15 \mathrm{~g}$ (of $235 \mathrm{U}$ )

$250 \mathrm{~g}$ (of $235 \mathrm{U}$ )

$500 \mathrm{~kg}$

$500 \mathrm{~kg}$

$500 \mathrm{~kg}$

$2 \mathrm{~g}$

$1 \mathrm{~kg}$ (of ${ }^{6} \mathrm{Li}$ )

goal of this regulation is to prevent or detect without delay the disappearance, loss, theft or diversion of nuclear materials, or equipment containing these materials regardless of their chemical or physical form.

The text of this regulation, the Code of Defence, determines the current regulatory framework related to the protection and control of nuclear materials relying on three main principles:

1. licenses are mandatory for anyone desiring to undertake significant activities in the following fields: import, export, storage, use and transport of nuclear materials;

2. operators are responsible for the implementation of physical protection of nuclear materials, and control and accountancy measures, under the control and inspection of the national Authority;

3. a penalty system in particular for non-declaration of theft, loss or diversion of nuclear materials.

The decree $n^{\circ}$ 2009-1120 of September 17, 2009 specifies the different types of nuclear materials included in the French regulations, which are fissile and fertile materials and those identified as likely to be used in the creation of a nuclear weapon. They are listed as: plutonium, enriched uranium with $20 \%$ or more of uranium-235, enriched uranium with less than $20 \%$ of uranium-235, natural and depleted uranium, thorium, tritium, deuterium, and lithium enriched in lithium-6.

This decree also establishes three regulatory regimes, based on the nature and quantity of the nuclear materials involved, as presented in Table I. 
1. Licensing: for significant quantities of nuclear materials, a licence from the competent Authority is mandatory.

2. Declaration: below a specified nuclear material mass threshold, no preliminary licence is required but a simple annual declaration of activities undertaken.

3. Exemption: no specific requirements for the operator but the quantities of nuclear materials held must be very limited.

In France, operators under the declaration regime are called "declarants".

Finally, additional decrees complete the legal framework. In particular, the Order of May 31, 2011 stipulates technical arrangements related to the control, accounting and physical protection of nuclear materials under the declaration regime. It specifies the rules to be followed regarding supporting documents justifying inventory changes and inventory taking.

It is worth noting that in France, safety and radiation protection are subject to specific regulations and authorities. These regulations also apply to most of the nuclear materials, except deuterium and lithium, which are not radioactive.

\section{Activities of declarants}

Declarant activities concern the medical, industrial, research and education fields and, in some rare cases, artistic uses. These activities are described in detail in Table II for each type of nuclear material. One can notice the diversity of uses of nuclear materials in non-nuclear fields.

Annual declarations, as described below in Section 3, provide precise figures on the inventory of nuclear materials held by the "small-scale holders" population, which gathers French operators under the declaration and the exemption regimes. Figure 1 provides an overview of this population regrouped by activity fields based on the declarations of the year 2009. At the end of 2009, approximately 243 declarants were identified in France and 314 operators holding nuclear materials under the exemption regime, including 171 operators who declared not to be in possession of any kind of nuclear material. Industrial radiography and medical radiotherapy users represent the highest population of operators within the declaration regime (more than $71 \%$ ). On the contrary, the majority of operators working in the research field belongs to the "exemption regime" category as most of them are in possession of small quantities of chemical products such as uranyl or thorium oxides, acetate or nitrate used for analyses or deuterated solvents used in Nuclear Magnetic Resonance techniques. 
TABLE II

Application fields of nuclear materials owned by declarants.

\begin{tabular}{|c|c|c|}
\hline Type of nuclear material & Uses & Civilian fields \\
\hline \multirow{2}{*}{ depleted uranium } & Radiation shielding & $\begin{array}{l}\text { Industrial gamma radiography } \\
\text { Medical radiotherapy }\end{array}$ \\
\hline & Balance weights & $\begin{array}{l}\text { Aeronautics } \\
\text { Oil-well drilling }\end{array}$ \\
\hline thorium & Welding electrodes* & Metallurgy \\
\hline \multirow{2}{*}{$\begin{array}{l}\text { *except for alloy with a } \\
\text { content of thorium under } \\
5 \% \text { in mass }\end{array}$} & Aircraft alloys * & Air museums \\
\hline & Chemical products & $\begin{array}{l}\text { Suppliers of chemical products } \\
\text { Laboratories } \\
\text { Pharmaceutics }\end{array}$ \\
\hline \multirow[t]{2}{*}{ natural uranium } & Chemical products & $\begin{array}{l}\text { Suppliers of chemical products } \\
\text { Laboratories } \\
\text { Pharmaceutics }\end{array}$ \\
\hline & Dye for crystals & Crystal manufactures \\
\hline deuterium & Solvents & $\begin{array}{l}\text { Laboratories, NMR (Nuclear Magnetic Resonance) } \\
\text { techniques }\end{array}$ \\
\hline \multirow[t]{2}{*}{ tritium } & $\begin{array}{l}\text { Radio luminescent } \\
\text { devices }\end{array}$ & $\begin{array}{l}\text { Aeronautics } \\
\text { Watch manufactures }\end{array}$ \\
\hline & Radiotracer & $\begin{array}{l}\text { Hospital } \\
\text { Laboratories }\end{array}$ \\
\hline $\begin{array}{l}\text { highly enriched uranium } \\
\text { plutonium }\end{array}$ & Sealed sources & Research and Measurements \\
\hline
\end{tabular}

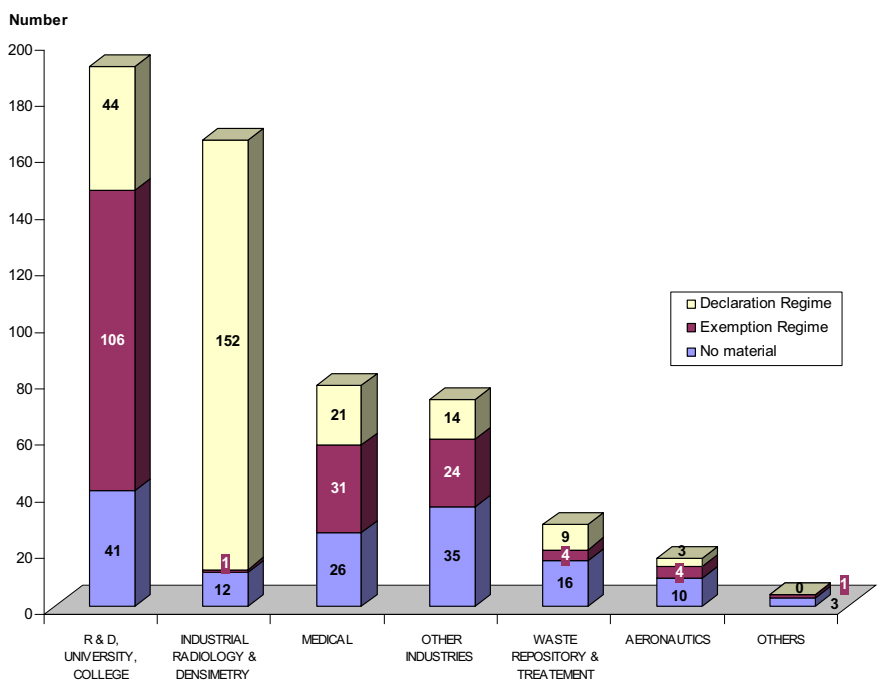

Figure 1 - Inventory declarations of nuclear materials regrouped by activity fields on December 31, 2009. 


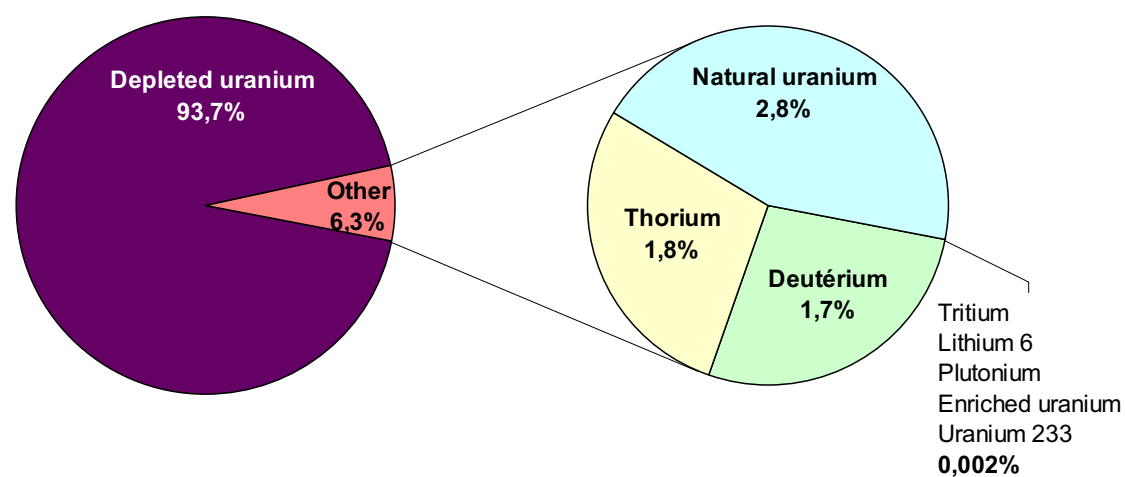

Figure 2 - Mass distribution of nuclear materials held by declarants (2009 status).

(The category "No material" corresponds to operators who declared not to be in possession of any kind of nuclear material.)

Each operator with a nuclear material quantity exceeding the exemption threshold once during the year falls within the declaration regime. This is the case even if the initial and the final inventories are lower than the declaration threshold.

As shown in Figure 2, depleted uranium represents, in mass, the main nuclear material held by small-scale holders ( $93.7 \%$ of the whole nuclear material stock).

The declared inventory of thorium and natural uranium is much less significant. Other nuclear materials only have a negligible proportion in the inventory held by declarants.

However, this mass distribution is not very useful for giving a relevant overview of the nuclear material really used by a small-scale holder, because the statutory thresholds which define the status of "declarant" are significantly different according to the type of nuclear material (see Tab. I). We cannot compare the mass of depleted uranium with that of tritium; expressed, respectively, in kilograms and about ten milligrams.

However, when we count the number of declarations per type of nuclear material, the distribution is significantly different, as shown in Figure 3. For example, deuterium is present in $9.2 \%$ of the declarations, whereas it accounts for only $2 \%$ in the nuclear material mass distribution held by the declarants.

Most of the depleted uranium held by declarants is actually found among industrial radiography or radiotherapy users, as shown in Figure 4. These materials are given the highest priority in terms of control by the Authority. 


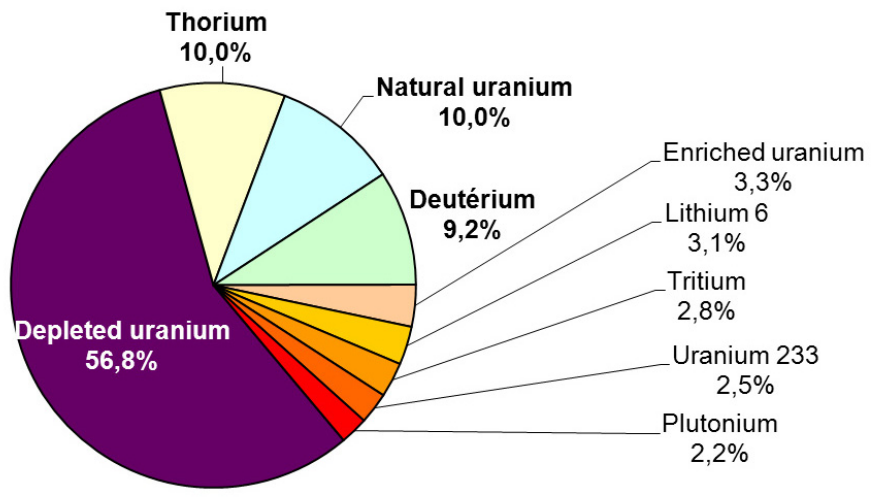

Figure 3 - Distribution of number of declarations of nuclear materials held by declarants (2009 status).

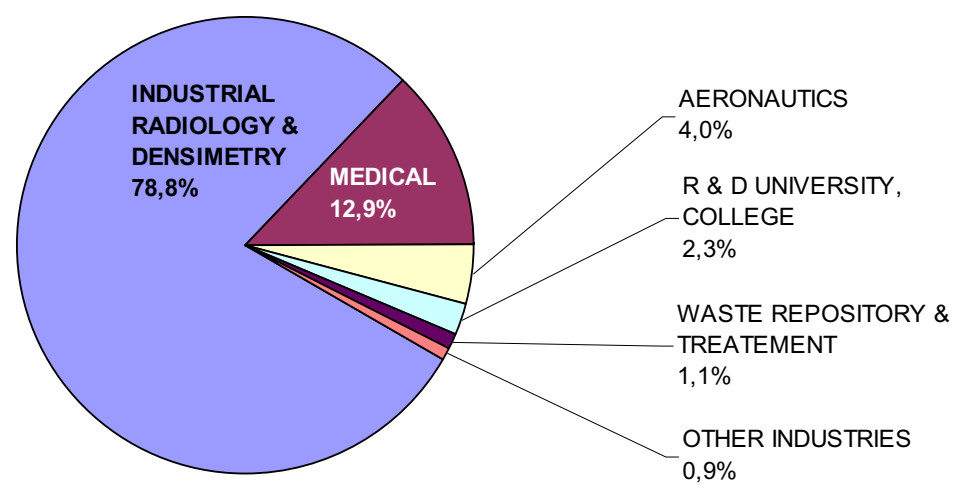

Figure 4 - Depleted uranium mass per application field (2009 status).

It should also be noted that among the 243 declarants, 204 hold a certain amount of depleted uranium, with a total quantity of about 15 tons of material. The following chart (Fig. 5) shows the distribution of depleted uranium among declarants.

Over the last ten years, one notes a significant reduction of approximately 5 tons of depleted uranium held by the declarants.

It is explained by the replacement of industrial gamma radiography and telegammatherapy by new techniques, such as industrial X-radiography or linear particle accelerators, which do not use sealed radioactive sources and consequently no internal shielding, made with depleted uranium. 


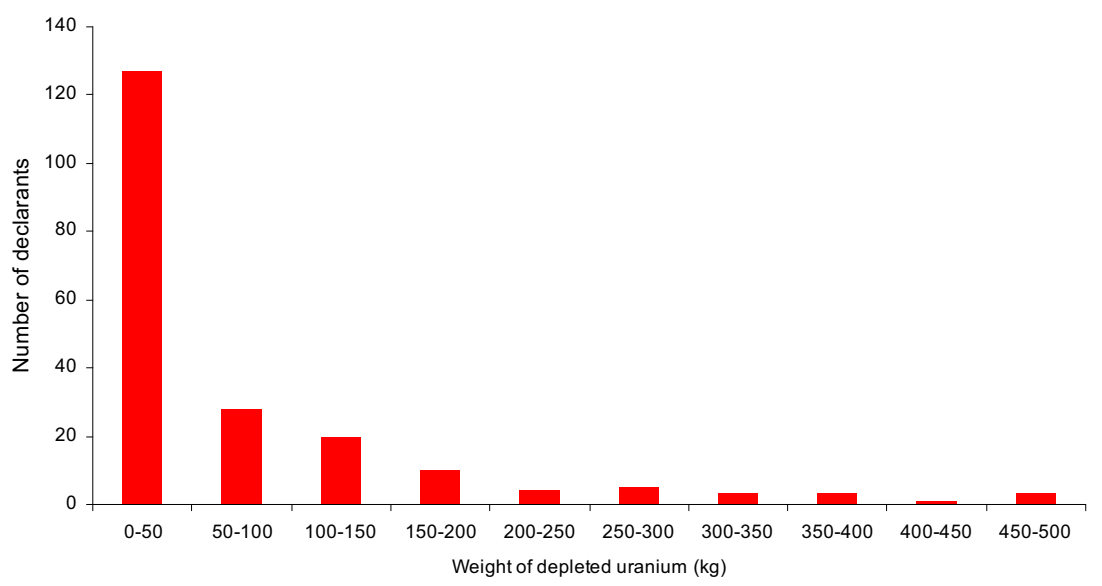

Figure 5 - Depleted uranium distribution among declarants (2009 status).

\section{Regulatory requirements related to the declaration regime}

Prior to the receipt of nuclear materials under the declaration regime, the operators involved must establish an initial declaration. This declaration is to be sent to the IRSN, acting as the technical support body for the competent Authority, and includes the following data:

- identification data (company name, address, etc.) and the name of its owner and operator who are legally responsible;

- types of activities concerned and localization of nuclear materials;

- description of nuclear material protection measures and physical follow-up system.

After this initial declaration, the operator must forward to the IRSN every year before January 31 st, the following data:

- inventory of nuclear materials on the 31 st of December of the previous year;

- detailed inventory changes which occurred during the previous year including production, consumption, reception or shipment of nuclear materials, providing the identification of shippers and recipients;

- maximum inventory of nuclear materials and inventory changes expected for the present year.

Inventory data must be provided for each category of nuclear materials defined in Table I. 
Declarants must also set up a local accounting system based on an accounting ledger. This ledger gathers chronological records of the various types of inventory changes that occur at the facility including production, consumption, reception or shipment of nuclear materials. The type of book to be used is not stipulated in the regulation. A paper copybook or a computerized system can both comply with this requirement, as long as it can be proven tamper-proof.

Declarants must also take measures to ensure the physical follow-up of nuclear material held, in order to know at any time where nuclear materials are located.

The operator must keep records of all supporting documents dealing with transactions involving nuclear materials as justifications of the inventory changes, for at least five years.

Before filling in the annual declaration, the operator must carry out a physical inventory to ensure that all nuclear materials present in the facility are correctly listed in the physical follow-up system.

It is also recommended that the operator periodically checks the presence of the nuclear materials at their expected location, especially when the device containing the materials is not used frequently.

Finally, the declaration also has to describe the main features concerning facility layout related to surveillance and physical protection of materials. These features must be adapted to the use and the qualities of nuclear materials. Regarding physical protection requirements, the Authority requires that nuclear materials are kept at least under lock and key, and keys should be accessible to authorized personnel only. Alarm system and guards are not mandatory, but in certain specific cases, the Authority requires an alarm system.

\section{Enforcement of the declaration regime requirements}

As previously mentioned, the IRSN acts as the technical support body of the competent Authority. IRSN missions include centralizing all declarations on nuclear materials, especially those submitted by owners of small quantities of nuclear materials.

Every year, a declaration form is sent by the IRSN to holders formerly identified as holding nuclear materials without needing a licence from the competent Authority. This form is drawn up on an evolutionary basis and can be changed based on experience and control objectives. The detection of new owners is ensured by investigations of the IRSN but also by the commitment of licensed companies. Indeed, companies under the licensing regime have to declare on a 
daily basis any change occurring in their nuclear material inventory. This includes all transfers of nuclear materials, for which the identity of companies sending or receiving the nuclear materials has to be specified. In the same way, the information made available in annual declarations by declarants is used to detect new or unknown owners of nuclear materials.

The IRSN is also in charge of evaluating the declarations returned by declarants. The evaluation consists of carrying out consistency checks with the previous declarations and making crosschecks and comparisons between the information forwarded by other declarants or submitted by licensed companies.

Declarants whose declared nuclear material inventory comes close to or exceeds the thresholds corresponding to the licensing regime are identified. Those submitting declaration forms containing missing, suspicious or non-reliable information are contacted and asked for new declarations comprising necessary corrections. The analysis of such cases can lead to on-site inspections if necessary.

If a declaration ever mentions the loss of nuclear materials, it is assigned the highest priority in the analysis and results in immediately informing the competent Authority. Once checked, the data are processed in the centralized national accounting database managed by the IRSN. This database also contains up-to-date general information related to the company, including its name and address, its field of activity, and the names and phone numbers of the persons legally responsible or appointed as the main official contact for questions referring to the nuclear materials declared. It contains the data taken from every annual declaration related to the quantity and nature of the nuclear materials.

The centralized data within the IRSN database forms a useful tool as it implies systematic and efficient checks of annual declarations, making quick detection of irregularities and problematic cases possible. The national database is used to provide any information required by the competent Ministry. In addition, it is a useful support tool to provide data in view of on-site inspections.

\section{On-site inspections}

On-site inspections are carried out by sworn and accredited inspectors. They are also a pertinent tool in enforcing the declaration regime requirements. Inspection programs are established after the analysis of annual declarations but also on the basis of specific events pertinent to a declarant or to a field of activities. The IRSN is also involved in the technology watch of fields involved in the use of nuclear materials, which can also lead to on-site inspections. These actions allowed inspectors to carry out 8 inspections in 2010 at the facilities of declarants. 
The main points of an inspection are:

- to remind the declarant of the national regulation related to control and protection of nuclear materials;

- to remind the declarant of the links between this regulation and others concerning radioprotection or radioactive source management (if needed);

- to check the compliance with the regulation and particularly with the order of May 31, 2011. In particular, inspections allow evaluating the local nuclear material accounting system implemented by the declarant;

- to check the documents related to these requirements;

- to check the correctness and the completeness of the previous physical inventory (portable detection devices adapted to the nature and the quantity of radioactive materials are used);

- to analyze the arrangements made by the operator to ensure the physical protection of nuclear materials.

After the completion of an inspection, inspectors send a report to the competent Authority, suggesting, if needed, corrective actions to be undertaken by the operators. The competent Authority notifies the declarant by letter of any noncompliance with the regulation and in the event of serious or repeated infringements, the competent Authority shall decide whether an appropriate penalty should be imposed.

274 on-site inspections carried out since 1995 have provided the IRSN with a sound knowledge of the use of nuclear materials held by small-scale holders in France. This allows the IRSN to play a main role in the preparation and implementation of the regulatory documents concerning the use of nuclear materials in the medical, industrial and research sectors on behalf of the Authority. It also allows the IRSN to identify specific issues and raise the attention of the Authority whenever necessary.

During the past few years, the few known losses of nuclear materials as shown in Table III were due to the lack of knowledge of declarants concerning nuclear material management. Most of the time, unused or damaged devices were involved.

Concerning the rare thefts that have involved small quantities of depleted uranium, most of them have taken place due to a lack of surveillance, including during a very short moment, of the vehicles transporting industrial gammagraphy equipment. In all cases, the motive was to steal the vehicle rather than the nuclear materials themselves. 
TABLE III

Events declared during the 2001-2011 period.

\begin{tabular}{lll}
\hline & Lost & Discover \\
\hline events number & 18 & 31 \\
depleted uranium mass & $778 \mathrm{~kg}(13$ events $)$ & $1223 \mathrm{~kg}(18$ events $)$ \\
thorium mass & $5.35 \mathrm{~kg}$ & $8.64 \mathrm{~kg}$ \\
${ }^{3} \mathrm{H}$ mass & $0.53 \mathrm{~g}$ & $0.30 \mathrm{~g}$ \\
other & Few grams of natural uranium & $0.01 \mathrm{mg}\left(2\right.$ sources of Pu and 1 source of $\left.{ }^{233} \mathrm{U}\right)$ \\
& & $19 \mathrm{~g}$ (enriched uranium) \\
\hline
\end{tabular}

\section{Conclusions}

In France, a detailed and comprehensive regulatory system has been set up for small-scale holders of nuclear materials.

The enforcement of this system relies not only on centralizing and analyzing the data submitted by operators but also on-site inspections.

The inspections are carried out by sworn and accredited inspectors under the authority of the competent Ministry and provide a global overview of the arrangements implemented by operators to ensure compliance with the requirements of the declarant regulation and an evaluation of the risks of theft or loss of the nuclear materials held in the facilities. Experience has shown that, even though the materials possessed by small-scale holders have a low sensitivity in terms of nuclear proliferation, the consequences of a malevolent or incidental event involving low quantities of nuclear materials may harm the corporate image of the holder in question. The IRSN's actions contribute to a better understanding of the regulatory requirements by operators and offer the French Authority the guarantee that the control practices of operators are consistent with the regulatory framework. 